\title{
De masonería, control y otras lealtades fraternales: el rescate de Porfirio Díaz por un hermano masón
}

\author{
Guillermo de los Reyes Heredia \\ Doctor por la Universidad de Pennsylvania (2004). Profesor Asociado del Departamento de Estudios \\ Latinoamericanos y director de Undergraduate Studies, Universidad de Houston, Estados Unidos. \\ Correo electrónico: jgdelosr@central.uh.edu
}

DOI: http://dx.doi.org/10.15517/rehmlac.v7i2.22693

Fecha de recibido: 29 de septiembre de 2015 - Fecha de aceptación: 15 de noviembre de 2015

Palabras claves

Masonería, Porfirio Díaz, Gran Dieta Simbólica, Logia La Parafite Union, fraternidad masónica

Keywords

Freemasonry, Porfirio Díaz, Symbolic Grand Diet, Lodge La Parafite Union, Masonic brotherhood

\section{Resumen}

En este artículo se explora el papel que jugó Porfirio Díaz dentro de la masonería y su relación con dicha institución. Se analiza una de las historias que comprueban que Díaz logró ciertos beneficios gracias a su afiliación masónica desde antes que fuera presidente de México. Esta historia narra la manera en que Díaz logró entrar de contrabando a México con la ayuda de un hermano masón en 1876, después de su breve exilio en Nuevo Orleans a bordo del buque de vapor, "City of Havana". En un principio se pensaba que ésta era simplemente una leyenda más del folklore que envuelve a la masonería. Sin embargo, dos testimonios, ambos de masones que iban en el mismo barco ratifican la historia que incluso el mismo historiador de la masonería norteamericana, William Deslow, catalogaba como un incidente, "no verificado."

Asimismo, se describe cómo Díaz promovió la unificación de las logias del rito escocés en una institución que se llamó La Gran Dieta Simbólica. La razón principal por la cual Díaz promovió tal unificación, como se afirma en este artículo, fue para llevar a cabo su plan de pacificación nacional. Díaz sabía que tenía que obtener el control de la masonería para evitar que ésta le causara problemas para lograr el orden y progreso que caracterizó a su gobierno. Por tal motivo, el dictador siempre vigiló que ni la masonería, ni cualquier otra institución que hubiera podido tener cierta influencia en la sociedad estuvieran fuera de su control.

\begin{abstract}
This article explores the role that Porfirio Díaz played in Freemasonry and his relationship with such an institution, analyzing one of the stories that proves that Díaz benefited from his Masonic affiliation before he was president of Mexico. This story tells how Díaz managed to smuggle himself into Mexico with the help of a brother Mason in 1876, after his brief exile in New Orleans aboard the steamship, "City of Havana". At first, it was widely believed that such a story was simply a legend, part of the folklore that surrounds Freemasonry. However, two witnesses, both Masons, who were in the same boat with Díaz, confirm the veracity of the tale that even William Deslow, the historian of American Freemasonry,, cataloged as a, "not verified" incident.

In addition, it studies how Díaz promoted the unification of the Scottish Rite lodges in an institution called The Symbolic Grand Diet. The primary reason why Díaz promoted such unification, as stated in this article, was to carry out his plan of national reconciliation. Díaz knew he had to gain control of Freemasonry to avoid future confrontations and trouble. He didn't want anybody to interfere with his governmental policy
\end{abstract}


of order and progress. Therefore, the dictator always made sure that neither masonry nor any other institution that had substantial influence in society were out of his control.

\section{Introducción}

La presidencia de Porfirio Díaz ha sido un tema de amplia discusión dentro de los ámbitos académicos y políticos. La represión, el excesivo control de todos los sectores políticos y sociales, el progreso sin desarrollo, la pax profiriana, la política de pan o palo, la diplomacia porfirista, entre otros, han sido los temas centrales de análisis sobre el dictador mexicano. Poco se ha estudiado sobre el papel que Díaz jugó dentro de la masonería y su relación con dicha institución. Por consiguiente, en este ensayo me propongo analizar algunos aspectos de la participación de Porfirio Díaz en la masonería, su relación con esta institución y la manera en que la uso y controló para sus propósitos y fines políticos. Para ello, me centraré en una de las historias que comprueban que Díaz logró ciertos beneficios gracias a su afiliación masónica desde antes que fuera presidente de México. El suceso que aquí estudio narra la manera en que Díaz logró entrar de contrabando a México con la ayuda de un hermano masón en 1876, después de su breve exilio en Nuevo Orleans a bordo del buque de vapor, "City of Havana". En un principio se pensaba que ésta era simplemente una leyenda más del folklore que envuelve a la masonería. Sin embargo, dos testimonios, ambos de masones que iban en el mismo barco ratifican la historia que incluso el mismo historiador masónico de la masonería norteamericana, William Deslow, catalogaba como un incidente, "no verificado".

Por otro lado, también discuto algunas de las estrategias que Díaz utilizó para lograr la unificación de las logias del Rito Escocés Antiguo y Aceptado en una institución a la que bautizó como la Gran Dieta Simbólica. Propongo que el motivo principal por el que Díaz promovió tal unificación fue para obtener más fácilmente el control de la masonería, tenerlos como aliados y de esta manera lograr su plan de pacificación nacional. Díaz sabía que tenía que obtener el control de las logias masónicas para evitar que éstas le causaran problemas para lograr el orden y progreso que caracterizó a su gobierno. Era imperativo que se unificaran las logias para evitar a toda costa que se siguieran dando las rivalidades y luchas que caracterizaban a las filas masónicas en el siglo XIX. Por tal motivo, el dictador siempre vigiló que ni la masonería, ni cualquier otra institución que hubiera podido tener cierta influencia en la sociedad estuvieran fuera de su control.

\footnotetext{
${ }^{1}$ William R. Deslow, 10,000 Famous Freemasons (Richmond, VA: Macoy Publishing \& Masonic Supply Co., 1957), Vol. I, 313.
} 


\section{Ficción o realidad: la importancia de las fuentes primarias}

Detrás de los estudios biográficos y prosopográficos de hombres y mujeres ilustres que han sido clave en la historia de sus respectivos países, siempre existen las historias fantásticas y leyendas sobre dichos próceres. Estas narraciones sobre algún hecho histórico o sobre algún personaje de la historia abundan dentro de los estudios históricos de la masonería. Como arguyo en Herencias secretas: Masonería, política y sociedad en México (Puebla: BUAP, 2009), hay una obsesión por afirmar que los políticos importantes del siglo XIX en América Latina formaron parte de las filas masónicas y que gracias a ello se logró tal o cual revolución. Muchas de estas afirmaciones se hacen sin un fundamento o base científica; por ello, muchos de los y las estudiosos/as de la masonería han dedicado parte de sus trabajos a aclarar estas afirmaciones y a destruir argumentos basados en la ficción y las narrativas fundacionales sin un fundamento histórico comprobable -ambas típicamente promovidas por los mismos miembros de la masonería o por sus detractores ${ }^{2}$. De hecho, en el IV Simposio Internacional de Historia de la Masonería y los Movimientos Asociativos Latinoamericanos y Caribeños: Prácticas Asociativas y Modernidad, Siglos XVIII - XXI, llevado a cabo en San José, Costa Rica durante noviembre de 2015, hubo varias mesas redondas y ponencias en las que se discutió ampliamente la importancia de la verificación de las fuentes primarias y comprobación de datos antes de aventurarse afirmar que dicho personaje fue masón o no, sin tener la evidencia necesaria. Se habló que es responsabilidad de los y las estudiosas y toda persona que estudie este tema tener mucha cautela al sacar conclusiones sin tener la documentación necesaria y/o la fuente primaria que las respalden. Por otro lado, también en las narrativas fundacionales de cada nación existen historias hiperbólicas que enarbolan y ensalzan a los héroes nacionales, presidentes o políticos. Muchas de estas historias están llenas de elementos ficticios que son manipulados para hacer dichas narrativas fundacionales más impactantes y adecuadas para desarrollar y promover esas comunidades imaginadas, como las ha llamado Benedict Anderson ${ }^{3}$, que son básicas para fomentar los sentimientos nacionales y promover los nacionalismos. Por ello, abundan estas historias maravillosas de los héroes nacionales tanto en el folklore de las historias nacionales como en el de las masonerías alrededor del mundo.

En lo referente a Porfirio Díaz ${ }^{4}$, una de las historias sobresalientes, de especial interés para los historiadores masónicos, es la historia de su rescate por un hermano masón,

\footnotetext{
${ }^{2}$ Véase, José Antonio Ferrer Benimeli, Bibliografía de la masonería: introducción histórico-crítica. (Madrid: Fundación Universitaria Española, 1977).

3 Benedict Anderson, Imagined Communities: Reflections on the Origin and Spread of Nationalism, (New York, Verso, 1983)

${ }^{4}$ El caso de Porfirio Díaz no es la excepción, existen otros casos como lo he mencionado en mi artículo intitulado, "Freemasonry and Folklore in Mexican Presidentialism". Journal of American Culture Vol, 20.2,
} 
en la barra de Tampico, antes de que éste fuera presidente en junio de 1876. De hecho, muchos estudiosos del tema pensaban que se trataba de una historia ficticia ya que no se habían encontrado fuentes primarias que la validaran. Tal historia se consideraba como ficción narrativa, parte de los tantos mitos, leyendas o historias fantásticas que envuelven a la masonería ${ }^{5}$. No obstante, en los archivos correspondientes a la Logia la Parfaite Union, que forman parte del acervo de la Gran Logia de California, en San Francisco, se encuentra un manuscrito en el cual se describe parte de la historia, arriba mencionada, basada en la perspectiva de Alexander K. Coney, contador del barco "City of Havana” en el que viajaba Porfirio Díaz". Asimismo, existe un documento manuscrito de Don Manuel Gutiérrez Zamora que se encuentra en manos de la familia del profesor Renato Gutiérrez Zamora en la ciudad y puerto de Tampico, Tamaulipas, México ${ }^{7}$. Gutiérrez Zamora fue testigo ocular fungía como agende de correos a bordo del buque de vapor "City of Havana", y en dicho manuscrito narran de una manera muy exhaustiva, con la pluma de un cronista, el salvamento de Porfirio Díaz. Cabe mencionar que la narración de los hechos por parte de Gutiérrez Zamora es notablemente más detallada que el documento de la Logia La Parfaite Union y es narrada en primera persona, mientras que la de San Francisco en tercera persona, es decir, es un discurso pronunciado por el orador de dicha logia sobre lo sucedido, basado en lo que Coney vivió, pero no en sus propias palabras ${ }^{8}$.

Por otro lado, el objetivo del manuscrito de Gutiérrez Zamora es presentar una crónica muy fiel y detallada de lo acontecido a bordo del vapor "City of Havana” en 1876, mientras que el propósito del documento de San Francisco es dar un homenaje a Coney, en el cual se describen sus heroicas acciones masónicas al describir cómo éste ayudó a su hermano masón Porfirio Díaz, de quien también se habla con respeto y admiración por su

(Summer 1997): 61-69. Véase también, Guillermo de los Reyes, Herencias secretas: Masonería, política y sociedad en México. México, D.F.: Benemérita Universidad Autónoma de Puebla, 2009.

${ }^{5}$ Hay toda una variedad de estas historias, algunas de las cuales son verídicas y otras de origen cuestionable: soldados dando la seña masónica a punto de ser escalpado por Indios Rojos, marineros izando una bandera azul con el cuadro y brújulas pidiendo así ayuda. Véase, e.g. Brian J. Bennett, "El Primer Masón Aborigen Australiano", Newsletter (Logia de Investigación CC, Irlanda, 1992), s. p.

${ }^{6}$ Dicho manuscrito tiene como título: “A Master Mason's Word of Honor and a Brother who Refused Fifty Thousand Dollars for it, Alexander K. Coney, Preceding Remarks by the Speaker”. Gran Logia de California, Archivo 17, s/f. Es importante notar que este es un discurso dado aparentemente dado en una reunión de la Logia La Parfaite Union.

7 Testimonio de Manuel Gutiérrez Zamora, "El salvamento de Don Porfirio Díaz frente a la barra de Tampico", manuscrito propiedad de la familia Gutiérrez Zamora. Tuve la oportunidad de hablar con la familia para localizar el documento original, el cual tiene la familia del profesor Renato Gutiérrez Zamora. Para este artículo he usado una transcripción del mismo publicada en, Historia mexicana 5, no. 1 [17] (jul. sept., 1955): 62-85

${ }^{8}$ En mi libro Herencias secretas (véase capítulo 3) pensaba que había sido narrado por Coney, pero al verificar nuevamente el documento cuando estuve en San Francisco en agosto de 2015, me pude percatar que donde parece que Coney es el que firma, es una cita entre comillas de una petición que hace Coney y que el orador quiere resaltar. 
valentía 9 . Ambos manuscritos ratifican que Díaz logró ciertos beneficios gracias a su afiliación masónica y que por lo menos en su periodo previo a la presidencia y a principios de su mandato, Díaz tiene una cercana relación con la masonería. Asimismo, ambos documentos subrayan la entereza, decisión y espíritu revolucionario de Porfirio Díaz. La historia de Gutiérrez Zamora narra la manera en que fugitivo logró entrar a México después de su breve exilio en Nuevo Orleans a bordo de un barco de vapor norteamericano con la ayuda de varios hermanos masones ${ }^{10}$. Hay notables diferencias en las historias en lo que respecta a cómo se enteró Coney que Díaz necesitaba su ayuda como discutiré más adelante. Sin embargo, en lo que respecta a la manera en que Díaz recibió ayuda por parte de sus hermanos masones (tanto mexicanos como estadounidenses) y cómo se benefició de su afiliación masónica, ambas historias presentan todos los elementos para llegar a estas conclusiones. A continuación discutiré con detalle la historia del rescate de Díaz que comprueba el apoyo que tuvo éste por parte de la masonería y a su vez ilustra un episodio más de la historia de México, que ha sido poco mencionado, sobre el regreso de Díaz después de su exilio en Nueva Orleans. A la par, discutiré las diferencias y similitudes entre las fuentes primarias que dan testimonio del suceso.

\section{Dos versiones, un objetivo: El salvamento de Porfirio Díaz por un hermano masón}

En 1876 Porfirio Díaz se encontraba huyendo del gobierno de Sebastián Lerdo de Tejada (1872-1876), ya que éste no estaba muy contento por las rebeliones encabezadas por el héroe de Tuxtepec contra la reelección del presidente Lerdo. De hecho, el gobierno había ofreció una recompensa de cincuenta mil dólares a aquél que entregara la cabeza de Díaz, vivo o muerto. Por ello, como mencioné anteriormente, Díaz decidió marcharse a los Estados Unidos fijando su residencia temporal en Nueva Orleans, cuidad de grandes vínculos masónicos con México. Durante su periodo en el exilio, Díaz buscó la manera de volver a su país sin ser descubierto para unirse a sus aliados, los revolucionarios de Tuxtepec y continuar la lucha contra la no-reelección ${ }^{11}$. Para esto, el futuro dictador acudió a otros exiliados políticos, al igual que a sus hermanos masones en busca de ayuda. La

\footnotetext{
${ }^{9}$ Es importante notar que el documento de San Francisco relata otro incidente relacionado con Coney y el Dr. Herrera, quien fuera el médico de cabecera del General Labastida, suegro de Coney. Se relata la petición de la exhumación del cuerpo del Dr. Herrera, obtener su corazón y entregarlo a las logias masónicas para realizarle un funeral masónico, ya que a su muerte, no se le había dado tal honor, de acurdo a Coney.

${ }^{10}$ En el manuscrito de San Francisco sólo se habla de la ayuda que le dio Coney a Díaz, pero en el documento de Tampico, además de Coney vemos que Gutiérrez Zamora y otros masones lo ayudan.

${ }^{11}$ Porfirio Díaz se revela contra Juárez primero y Lerdo de Tejada después por las intenciones reeleccionistas que dichos presidentes tenían. Lo irónico es que una vez que Díaz logra estar en el gobierno no respeta el lema de "sufragio efectivo, no reelección" que él mismo abanderaba. Véase, Elisa Speckman Guerra, "El Porfiriato", en Nueva historia mínima de México (México D. F.: El Colegio de México 2011).
} 
respuesta fue favorable para Díaz ya que lo hizo acreedor del apoyo de sus hermanos masones, lo cual le permite volver a México a continuar la lucha. De acuerdo al documento de la Gran Logia de California, un hermano masón (cuyo nombre no se menciona) puso a Díaz en contacto con Alexander K. Coney, miembro de la Logia la Parfaite Union No. $17^{12}$ de San Francisco y contador del barco de vapor "City of Havana" que partiría de Nueva Orleans a varios puertos de México, entre ellos Tampico, Tuxpan con destino final en el puerto de Veracruz. Sobre esto, el documento “A Master Mason Word of Honor" señala:

[Diaz] couldn't endure the isolation of being fugitive in disguise, and being a Freemason, it was a natural for him to seek the Fraternities' aid, as a duck would take the water-So he asked, he received-He sought, he found-He knocked, and the honor of Freemasonry opened onto him. Placing his trust in God and in a good brother from New Orleans, who would give him any assistance needed, when requested. He had not long to wait, for his trusted Brother knew what to do. He was well acquainted with Alexander K. Coney a Brother mason - a purser on the steamship "City of Havana" plying between New York, New Orleans, Havana and Mexican ports; and also knowing the steamer soon arrive in his city, he made the necessary arrangements with Díaz, to meet him at the ship's landing and when it arrived and when it arrived "they met agreeable to appointment" [énfasis en el original]. Díaz was introduced to Brother Coney - The signal Flag of Distress was raised, which none but the purser could understand, and grant and then too under the most trying and peculiar circumstances. It also might involve himself in great danger personally, and almost in a certainty cost the Brother in need, and assistance his life. When these two brethren met, it seemed as though they verily stood on the Five points of Fellowship - They consulted, agreed, and both pledged to each other their sacred word of honor "- A Master Mason's Word-" in safety or distress ${ }^{13}$.

En esta versión de la historia es evidente el interés por enfatizar la conexión masónica entre los protagonistas. Coney prometió ayudarlo dándole "su palabra sagrada de honor", la de un maestro masón, por ello, no lo iba a defraudar e iba hacer hasta lo imposible por salvarlo. Por consiguiente, para evitar que Díaz fuese descubierto, Coney lo registró con un nombre ficticio, Dr. Rodríguez de la Boza y lo escondió en un salón secreto del barco de vapor. El documento de la Gran Logia de California, no da detalles específicos sobre lugares, personas, situaciones secundarias, sólo se dedica a enfatizar los elementos claves que muestran el cumplimiento de la palabra de honor y algunos detalles como ya he

\footnotetext{
${ }^{12}$ Ese contacto pudo haber sido el Dr. Jonnes que es precisamente el acompañante de Díaz en el barco de acuerdo a la historia de Gutiérrez Zamora. La Logia la Parfaite Union fue establecida en 1851 y tenía una gran cantidad de miembros de México, América Latina y otras partes del mundo. Su ritual difería de otras logias californianas y frecuentemente recibían a visitas de países tan exóticos como Tahití.

13 “A Master Mason's Word", 2.
} 
mencionado anteriormente. En contraste, Gutiérrez Zamora si presenta muchos detalles, como es el caso del nombre falso que recibió Díaz, su acompañante, el momento en que lo salvan, entre muchas otras cosas. Al respecto apunta en su crónica: "En la noche antes de nuestra salida se presentaron dos individuos a bordo con boletos de pasaje hasta el puerto de Túxpam. El uno joven, de espejuelos, se llamaba Dr. Jonnes; y el otro, Dr. cubano homeópata Rodríguez de la Boza, según dicho del Dr. Jonnes, pues debo manifestar que Rodríguez de la Boza nunca se presentó en la cámara a la hora de las comidas y fuera de ella tampoco noté su presencia" " Gutiérrez Zamora sospecha mucho de dichos pasajeros, del supuesto doctor cubano porque nunca se le ve en público y del Dr. Jonnes porque, “[n]o sé qué motivo tendrá este hombre de decir que no ha vivido nunca en la República Mexicana, pues habla español bastante bien, y aunque muy cortado tiene modismos especiales de México" ${ }^{\prime 15}$.

Gracias a la narración de Gutiérrez Zamora se obtienen detalles importantes como los nombres de los personajes y los hechos claves, como el suceso en Tampico. Al tercer día llegaron a Tampico, el City of Havana ancló a un lado del vapor de guerra mexicano, "Independencia" y el bergantín goleta nacional, "Constante", perteneciente al capitán Ramírez. Una vez en Tampico, Gutiérrez Zamora narra la que quizás fue la principal razón que llevó a Porfirio Díaz a querer escapar inmediatamente del barco:

Poco más tarde se atracaron al vapor americano los demás chalanes. Subió a bordo un teniente coronel Arroyo, bajo de cuerpo, fornido y picado de viruelas, un señor mayor Ruiz, de figura simpática, delgado, trigueño y de mirada inteligente y algunos otros oficiales subalternos...p pero entre ellos figuraba un capitán, alto, calvo y de figura muy inteligente, modales muy decentes y hablaba con mucha finura y como hombre de muy buena sociedad...había subido casi toda la oficialidad y algunas o todas las mujeres de los soldados y gran número de éstos... Pasó la hora del lunch $y$ tuve el gusto de hacer conocimiento con el coronel Arroyo...comenzamos hablando sobre la política del país y sobre las posibilidades del triunfo del Plan de Tuxtepec reformado en Palo Blanco. Como el jefe de esas fuerzas debía ser gobernista, no expresé libremente mis opiniones, ni tampoco di color gobernista, sino empecé por hablar muy bien de la organización del ejército debida al C. general Ignacio Mejía, y me dejé llevar por su opinión, para no chicar en política desde el primer momento con el jefe de la fuerza federal a bordo del vapor City of Havana ${ }^{16}$.

En ese momento Gutiérrez Zamora no sabía de la presencia de Díaz en el barco, Alexander Coney y el Dr. Jones eran los únicos que lo sabían. Fue hasta después de la

\footnotetext{
14 "El salvamento", 62.

15 "El salvamento", 63.

16 "El salvamento", 64
} 
sobremesa y socializar con los del barco que Gutiérrez Zamora relata detalladamente el intento de Díaz de abandonar el barco, para evitar ser descubierto y porque estaban cerca de la barra de Tampico:

Yo me dirigía a mi camarote que estaba a babor...cuando escuché algo que caía, todo el mundo corría a curiosear a popa...A la curiosidad corrí también, y cuál sería mi sorpresa cuando vi nadando en pleno Golfo de México a un hombre que, en obsequio de la verdad, lo hacía muy bien. Me acerco al capitán Philips, que todavía estaba en el lugar primitivo, y le digo:

-¿Qué es eso capitán?

-No sé, creo que es el loco del doctor que se está bañando; salió de su camarote, bajó la escalera que conduce al W.C., y corriendo desnudo, se subió al empañetado de popa y se lanzó al agua de cabeza.

-Pues es preciso sacarlo, porque un tiburón se lo puede comerlos tiburones...

...en ese momento supremos, cuando arriábamos el bote, el Dr. Jonnes con fuerza nerviosa me detiene el brazo y me dice en inglés:

-Por Dios, Zamora, no boten el bote al agua, porque el hombre que va nadando es el general Díaz.

Un cubo de agua fría no me hubiera hecho en aquel momento la impresión que me hicieron las cortas pero rápidas palabras de Jonnes. Con el cabo entre las manos me acerco a Phillips y le digo: salvarle

-Capitán, ese hombre que está en el agua es el general Díaz; es preciso

Con flema muy inglesa me contesta:

-Es la única manera, pues si se tarda cinco minutos más los tiburones darán cuenta de él.

Fue una verdadera ansiedad el tiempo que tardó el bote en llegar junto al nadador, pues desde el momento en que vio venir la embarcación más se esforzaba por adelantar: su intención era, y eso se veía palpablemente, coger la popa del bergantín Constante y resguardarse en él, o, resguardado por este buque, coger la costa escondido de las miradas de los del vapor ${ }^{17}$.

De acuerdo a Gutiérrez Zamora el propósito de Díaz era huir del barco para no ser descubierto, sin embargo, como lo expresa en su manuscrito, había sido muy peligroso nadar hasta la costa, casi tres millas, debido a la furia del mar en esos momentos y a la marea. Además, parecía que Díaz había estado enfermo que lo había llevado a delirar. Una vez que el pequeño barco se acercó a Díaz, quien intentaba que no lo sacaran del mar, ya que pensaba que al sacarlo lo entregarían a las autoridades, lograron meterlo al bote y se aseguraron que no quisiera tirarse al mar nuevamente. Gutiérrez Zamora menciona que al

\footnotetext{
17 “El salvamento”, 67
} 
acercarse al barco él lo quería tapar con una "levita azul que tenía puesta y se la arrojé al bote para cubrirlo con ella", pero la levita cayó al agua. Desesperado el testigo ocular que cuenta esta historia comenta que, "[s]in pedir permiso, ni usar alguna frase cortés, me apoderé de una sábana y un cubre cama que tomé al acaso y volviendo a la amura del buque le dije a Bováis [el 2º . oficial que sacó a Díaz del agua]: -Cúbrelo bien, hasta la cabeza" ${ }^{\text {. }}$. Bováis siguió las instrucciones y al llegar al barco Díaz "pronunciaba palabras incoherentes que por estar cubierto por la colcha, no se entendía bien. Las primeras palabras que le dije al subir a bordo fueron: -Cállese Ud., que no lo han conocido...Como es natural todo el mundo quería curiosear...les dije: --Señores, aquí pasan solamente los facultativos, y los que no lo son, suplico que se retiren, pues ese hombre está bastante enfermo"19. En estos momentos, Gutiérrez Zamora se une al grupo de los masones que ayudan a Porfirio Díaz y hace todo lo posible para que nadie lo reconozca y junto con Alexander Coney comienzan a idear planes para sacar a Díaz del barco en alguna de las próximas paradas. Inmediatamente después de haberlo rescatado, el Dr. Jonnes le dice a Gutiérrez Zamora que Díaz quiere hablar con él, sobre esto el narrador de la historia apunta:

Cuando entré al camarote...estaba acostado en su litera, muy pálido, y todavía temblaba. Confieso que por mi parte tenía yo gran temor, no por mi persona. ¿Qué me hubiera hecho el gobierno del Sr. Lerdo si me prueban que estaba mezclado en este negocio? Despojarme de un destino o empleado enteramente subalterno que tenía de agente de correos, como sucedió después que me lo quitaron por telégrafo, dándoselo a un Sr. Jurado...muy amigo del Gral, Marcos Carrillo, comandante militar de la plaza de Veracruz...Si temía yo en esos momentos era por la personalidad del caudillo de la revolución, que si lo hubieran apresado, y tal vez fusilado, el Plan de Tuxtepec hubiera fracasado de seguro...mi madre, mi hermano Ignacio y toda la familia comprometida en la revolución...en fin tanto trabajo se perdería con la muerte del general Díaz, y ése era mi gran temor: el hacer el gran fiasco en momentos solemnes" 20 .

La pluma de Gutiérrez Zamora muestra su respeto y simpatía por Díaz, así como su afán por ayudarlo. No hay lugar a duda que el narrador de la historia quiere que Díaz continúe con su lucha por el pueblo mexicano, inclusive, menciona en su historia que él lo habría ayudado a escaparse personalmente de haberle revelado su identidad o haberlo planeado de otra manera como él le había propuesto antes a través del coronel Torres. Como alternativa, le prometió a Díaz, "que le iba a hablar al contador Coney, que era muy amigo mío, como un hermano [masón] y que éste le serviría"21. Aquí hay una posible

\footnotetext{
18 "El salvamento", 68.

19 "El salvamento", 69.

20 "El salvamento", 69-70.

21 "El salvamento", 71.
} 
discrepancia, ya que de acuerdo a Gutiérrez Zamora, Coney no sabe que Díaz está en el barco, pero en el documento de San Francisco, se dice lo contrario, de hecho se detalla cómo se conocieron. Mi hipótesis es que Coney, al haberlo dado su palabra de honor a Porfirio Díaz de mantener el secreto, no lo iba develar hasta que éste estuviera a salvo. Independientemente de si mi hipótesis es acertada o no, para fines de este trabajo, lo que quiero enfatizar es la manera en que se usó la fraternidad masónica y cómo ésta es un elemento clave en esta historia que salvó a Díaz de las fuerzas lerdistas y de otros enemigos. Cabe mencionar que Gutiérrez Zamora le da gran crédito a Coney, "[d]esde ese momento, el doctor don Alejandro K. Coney tomó la responsabilidad y trabajó mucho, muchísimo, para poder salvar al general don Porfirio Díaz."22 Relata Gutíerrez Zamora que hubo una ocasión en la que Coney le dijo a Díaz que podrían trasladarlo a un buque de guerra estadounidense que pasaba cerca de ellos y que él ya había hecho gestiones para ayudarlo, pero Díaz se negó contundentemente diciendo: "No quiero deber a los Estados Unidos nada absolutamente, a particulares amigos, ya sean de esa nación o de otra, ésa es otra cosa diferente",23.

Al zarpar el "City of Havana" de Veracruz hizo una parada por la noche para descargar. Coney y Gutiérrez Zamora decidieron que esa era la ocasión indicada para que Díaz abandonara el barco, especialmente porque ya se corría el rumor y se pensaba que ya sabían que Díaz estaba en el barco. Varias personas se unen a la empresa para salvar a Díaz, entre ellos: el general Juan de la L. Enríquez, Joaquín Alpuchem Manuel Caldelas, Abraham Aguirre, Joaquín Cruz entre otros. Vistieron a Díaz con la ropa que usan comúnmente lancheros del puerto de Veracruz y los llevaron a la lancha de Alpuche. Gutiérrez Zamora apuntala:

Después de cargada la lancha se desatracó del vapor e hizo rumbo al muelle de Veracruz...Don Juan Enríquez desde la casa de don Manuel Levi, que estaba frente del muelle, observaba con unos gemelos los movimientos de todos; parecía un general que teme perder una batalla... Cuando estaban a cierta distancia del fuerte, el pequeño bote de la lancha les sirvió para poner en tierra firme al Sr. General Díaz, que este, viéndose en tierra firme, exclamó con gusto estirando los brazos y las piernas: "Gracias a Dios que puedo estar derecho". Caminó en conversación con el señor Marañón algunos pasos hasta donde estaba el guía con los caballos, Marañon le entregó algún dinero, pistola, parque, y se despidió. El general Díaz montó a caballo y tomó el camino de Boca del Río. Un correo que se le mandó después "Sta. María" lo alcanzó en "La Matosa" lugar donde los defensores del plan de Tuxtepec se encontraban ${ }^{24}$.

\footnotetext{
22 "El salvamento", 72.

23 "El salvamento", 76.

24 “El salvamento", 84-85.
} 
De esta manera, la huida de Porfirio Díaz fue exitosa. Meses después Díaz se convirtió en Presidente de México y paga los favores a todos aquellos que lo ayudaron en esta empresa $^{25}$.

\section{La recompensa fraternal}

Al subir Díaz al poder hizo una invitación a su hermano masón Alexander Coney al Palacio Nacional. Este último aceptó complacido, viajó a la ciudad de México y fue escoltado hasta el Palacio Nacional para reunirse con Díaz. El documento de San Francisco es el único que narra esta visita. Al momento de la llegada Coney "was unshered through the lines of the officers with drawn swords at "present swords" [énfasis en el original] and then for the first time met (after what previously had transpired) Diaz as President of Mexico and Alexander K. Coney Purser on the "City of Havana" [énfasis en el original]". Después de los saludos correspondientes Díaz anuncia: "he aquí el hombre que me salvó la vida haciendo posible que me convirtiera en presidente de nuestro adorado país"27.

Como agradecimiento Díaz le dio un cheque A Coney de 50 mil dólares, ya que esa cantidad se había puesto como recompensa por su cabeza. Ante tal gesto, Coney se muestra agradecido y devolviéndole muy respetuosamente el cheque le respondió que él le había jurado ayudarlo bajo "la palabra de honor de un hermano maestro masón" por ello no podía aceptar el dinero. El Presidente Díaz comprendió que, en este caso, el ofrecimiento de dinero no era pertinente, por lo que le propuso ser Cónsul General de México en París, Francia. Tal gesto de gratitud por parte de Díaz agradó a Coney y aceptó. Posteriormente, Coney se naturalizó mexicano y fue Cónsul de México en París y, posteriormente, Cónsul de México en San Francisco ${ }^{28}$. Se debe notar que también Coney se vio beneficiado por la

\footnotetext{
${ }^{25}$ Archivo 17: Gran Logia de California, San Francisco. “A Master Mason's Word of Honor and a Brother who Refused Fifty Thousand Dollars for it, Alexander K. Coney, Preceding Remarks by the Speaker”. Véase también la descripción que hace William R. Denslow sobre dicho incidente en 10,000 Famous Freemasons, 313.

${ }^{26}$ Denslow, Famous Freemasons, 5.

27 Denslow, Famous Freemasons, 5.

${ }^{28}$ Como se dijo anteriormente, antes de encontrar en los archivos de la Gran Logia de California, en San Francisco no sabía si ésta era sólo una de las tantas leyendas en torno a la masonería. También se menciona una variante de esta historia en el libro de Meyer y Sherman: "Hay alguien entre nosotros que esperamos pronto ocupe la Silla Oriental de aquella Logia - el protector y salvador de un Gran Maestro Hermano, quien era fugitivo y con un precio de 50 mil dólares sobre su cabeza. Ese que alguna vez fue fugitivo, seguido y cazado aun hasta el borde mismo de la muerte, está ahora a la cabeza de toda la masonería real de este país, quien ha sido puesto en libertad a través de su complicidad - nuestro más adorado el ilustre hermano PORFIRIO DIAZ, $33^{\circ}$, Gran Maestro de Masones y Presidente de la República Mexicana - y el hermano que lo protegió en sus momentos de mayor desesperación que el ilustre hermano ALEXANDER K. CONEY, $32^{\circ}$, El Príncipe del Real Secreto de la Loge La Parfaite Union, No. 17, y Cónsul- General de México en San Francisco... "Haut le Calice! À la hauteur du front. Vive le Loge La Parfaite Union! À moi pour la batterie!
} 
hermandad masónica, lo cual es un elemento muy importante de co-fraternidad que se da en las filas de la masonería y de lo que hablo en Herencias secretas en la sección: La masonería como escuela de gobierno ${ }^{29}$.

La historia anterior en sus dos presentaciones, muestra que la filiación masónica ayudó a Porfirio Díaz a entrar a México, sin que sus enemigos lo pudieran atrapar. Por lo que se describe en los documentos, no fue una empresa fácil pero se logró el objetivo principal y nadie de los involucrados tuvo consecuencias negativas, particularmente gracias a que Díaz logró llegar al poder. De la misma manera, se corrobora, que los principios de hermandad masónica (a pesar de lo ocurrido por rivalidades políticas) pueden llegar a ejercer influencia en los individuos que en algunas ocasiones se extienden al ámbito político. Tal vez este acontecimiento contribuyó en que Díaz apoyara a la masonería y que, a pesar de sus intereses personales, no la alienara, ni le destruyera. Por otro lado, se puede apreciar que a pesar de que ambas versiones se presentan con registros, estilos y lenguas diferentes. Hay un común denominador: la hermandad masónica. De hecho, el documento de San Francisco tiene como objetivo claro y un tanto hiperbólico mostrar que los valores masónicos le dieron fuerza y entereza a Porfirio Díaz para lograr escapar y llegar a ser presidente de México: [Díaz] was not yet where he could call his life his own but Masonry had taught him that 'Time, Patience, and Perseverance would accomplish all things",30. Además en ese mismo manuscrito se expone a Porfirio Díaz como un ilustre masón. El público que recibe ese mensaje fueron los miembros de la Logia La Parfaite Union y tal vez otras logias y Grandes Logias que hayan recibido tal correspondencia, pero no era para un público en general. El manuscrito de Manuel Gutiérrez Zamora tiene como objetivo ser una crónica que va a dejar por escrito para la posteridad una de las hazañas claves en la vida de Porfirio Díaz, porque de no haberlo ayudado a escapar, tal vez otra sería su suerte. Gutiérrez Zamora quiere omitir nada y sólo quiere decir la verdad de lo que sucedió. A pesar de ello, no deja fuera el aspecto masónico, ya que identifica a Díaz, a Coney, al capitán del barco, Phillips y a el mismo como hermanos masones: "Me preguntó si Coney era masón, le contesté que sí, que hacía pocos meses había yo asistido a su logia, cuando le habían dado el 3er grado"31. En otro momento, cuando está discutiendo con el capitán Phillips sobre Porfirio Díaz: “- -Tal vez le hablen a V. sobre este asunto; V. es mi amigo y conoce mis opiniones; además V. sabe que un hermano está en peligro. Muy serio y secamente me contestó Phillips: - Mis deberes como hermano yo los sé, y dispénseme le diga que no quiero que nadie me los enseñe" ${ }^{, 32}$. Claramente hay un grupo de personas

Acclamation!". Michael Meyer y William Sherman, The Course of Mexican History (New York: Oxford University Press, 1987), 140.

${ }^{29}$ De los Reyes, Herencias, capítulo IV

30 "A Master Mason...", 4.

31 "El salvamento...", 71.

32 "El salvamento...", 73-74. 
claves que pertenecen a la masonería. Sin lugar a duda y por la manera en que está presentadas las historias, fue gracias a las sociabilidades masónicas y ha esta redes fraternales de apoyo que se logró salvar al que ese mismo año, 1876, se convertiría en presidente de México, ejerciendo el poder por más de treinta años.

\section{El compás y la escuadra en manos del dictador}

En la sección anterior presenté un suceso en el que Díaz recibió ayuda de sus hermanos masones, al grado de que muchos de ellos arriesgaron sus vidas para cumplir con su palabra de honor de hermanos masones. Sin embargo, ¿cuál fue la participación de Porfirio Díaz en la masonería antes de subir a la silla presidencial? Antes de llegar al poder, Díaz recibió gran apoyo por parte de la masonería ya que era miembro de la logia Fraternidad No. 1, como se muestra en la misiva que le envía Ignacio Pombo a Porfirio Díaz el 12 de febrero de 1869 en la cual le informa:

[F]ueron levantadas las columnas de esta Resp. $\therefore$ Log. $\therefore$ Fraternidad $N^{o} 1$ que desde el mes de noviembre de 186(roto) $\therefore \mathrm{V} . \therefore$ estaban caídas por causa de los acontecimientos políticos que han agobiado al país [asimismo, expresó:] recordándose que por vuestro alto gr. $\cdot$ sois Miemb. $\cdot$ nato de esa Resp. $\therefore \log .{ }^{33}$.

Lo anterior, es ratificado por el mismo Porfirio Díaz en la carta que envió el 27 de marzo de 1869, a Ignacio Pombo en la que le respondía, de su puño y letra (A.M.C.) ${ }^{34}$ :

Muy Y. $\therefore$ y ven $\therefore$ H. .

Tengo la honra de acusar recibo a vuestra pl. $\therefore$ fecha 12 de febrero de 1869 E. . con el cordial agradecimiento de la medalla inclusa con la que me honráis.

Por dicha pl. $\therefore$ quedo informado con satisfacción de que el día 22 de agosto de 1868 E. $\therefore$. V. $\therefore$ fueron levantadas las columnas de esa Resp.. Log. $`$ Fraternidad No.1 y de la cual tengo la honra de ser miembro activo.

Recibid I. $\because$ H. $\because$ el Osc. $\therefore$ de Paz y abrazo frat. $\bullet$ O. $\therefore$ S. $\therefore$ C. $\therefore$ L. $\therefore$ S. $\because$ Y. B. $\cdot$ O. $\therefore$ S. $\cdot$ C. $\cdot{ }^{35}$.

Este es solo un ejemplo de la participación activa de Porfirio Díaz dentro de las filas masónicas de México. Siempre pensando, como aquí propongo, sobre la importancia de

\footnotetext{
${ }^{33}$ Porfirio Díaz, Archivo del general Porfirio Díaz, memorias y documentos; prólogo y notas de Alberto María Carreño. VII, (México D. F.: Editorial "Elede," 1947), 218.

${ }^{34}$ Díaz, Archivo del general Porfirio Díaz, 219.

${ }^{35}$ Es importante mencionar, que en la carta enviada por Y Pombo a Díaz, mencionada anteriormente, le hacen saber a Díaz que se le otorgaría una medalla como distintivo a los miembros de la Gran Logia Fraternidad No. 1 de Veracruz. Archivo Porfirio Díaz, Alberto Ma. Carreño, Tomo VII, 218-219.
} 
tenerlos como aliados para lograr sus objetivos políticos. También se puede plantear que posiblemente las logias masónicas fueron para Díaz el lugar de preparación política, la cual se combinaba con la preparación que, como militar, obtenía en el campo de batalla. Como miembro de la fraternidad masónica, logró grandes privilegios debido a que era admirado por ser un afamado general ganador de varias batallas -era llamado el héroe del 2 de abrily más aún por su condición de Presidente de la República. Es relevante mencionar que es una gran tradición masónica (aunque no se menciona en sus estatutos, ni en sus libros) la de invitar a sus filas a hombres ilustres que pueden poner en alto el nombre de la fraternidad. Por consiguiente, Porfirio Díaz jamás desaprovechó el lugar que los masones le dieron y algunas veces los utilizaba para sus beneficios. La masonería fue vista por Díaz como uno de los medios para obtener la presidencia y lograr muchos adeptos dentro de esas sociedades. Esto se evidencia en una carta que le escribió Luis Pombo a Porfirio Díaz el 13 de agosto de 1870:

Muy señor mío y fino amigo:

La violencia de mi marcha para esta capital me impidió pasar y despedirme de usted como deseaba; pero a mi hermano encargué que hiciera a usted presentes mis recuerdos, y le manifestara la causa de no haberlo saludado de despedida.

Impuesto a los buenos deseos de usted para establecer en esta ciudad el Rito Nacional Mexicano, luego que llegue a ésta propuse a la G.'. L.' . que autorizarán a usted para la creación de un taller, y mi proposición fue unánimemente aceptada, y hoy me entregaron la carta de autorización, que no le remito original porque está en Bristol, y se ajaría mucho; pero entre tanto puedo situarla en esa, le acompaño una copia autorizada de la carta, con la que ya se pueden emprender los trabajos de las liturgias de los grados $1^{\circ}, 2^{\circ}$ y $3^{\circ}$ que son los que por hoy se remiten.

Próximamente mandaré autorizaciones y otras cosas que faltan.

Antes de concluir ésta, lo felicito porque le ha tocado en suerte establecer en nuestro Estado la masonería, y abrir las puertas de la luz con la antorcha de la razón así como más de una vez a usted libertado con su espada, de la tiranía y del yugo e[x]tranjero.

Vea usted en qué le puedo ser útil su Atto. amigo y Affmo. S. que B.S.M. Luis Pombo ${ }^{36}$.

Nuevamente el intercambio de Díaz con Luis Pombo reafirma la relación que durante este tiempo Díaz tuvo con los masones. Se aprecia el interés por parte de sus hermanos masones de involucrar al gran héroe de guerra y futuro líder la masonería. Por otro lado, Díaz les daba un lugar en su agenda política, para lograr tenerlos de su parte y conseguir mayor fama, popularidad y apoyo por parte de los masones que lo ayudarían a lograr adeptos dentro de las filas masónicas. Se debe tener en mente que en esta época Díaz

\footnotetext{
${ }^{36}$ Archivo del General Porfirio Díaz, Tomo IX, 9-10.
} 
tiene en su contra a los juaristas y a los lerdistas. No se ha comprobado que Díaz instituyó la masonería en algún estado, a lo que Pombo se refiere es que Porfirio Díaz contribuyó a la formación de algunas logias. Por otro lado, tenía bien clavados sus ojos en el futuro y veía en algunos miembros de la masonería a las personas ideales que estarían trabajando con él en su reelección presidencial. Asimismo, era consciente de que en las filas de la masonería se engendraban y preparaban líderes, los cuales, había que identificar para invitarlos a formar partes de su gobierno, para mantenerlos cerca de él y poderlos controlar. "Se decía entonces [comenta Luis Zalce y Rodríguez] que en tales tendencias de fraternización y de fecunda actividad asomaba la mano del ilustre hermano General Porfirio Díaz, Presidente de la República y amigo personal de la Familia Pombo" 37.

\section{Porfirio Díaz en el poder: “orden y progreso" en las filas masónicas}

En el momento en que Porfirio Díaz asciende al poder, venciendo a los otros bandos rivales (1876), tenía como objetivo lograr la pacificación del país, para de esta manera lograr el progreso económico y la gobernabilidad de México. Meses después de alcanzar el poder, Díaz declaró: "He aquí la noble y grande tarea que os pertenece: restablecer la autoridad suprema de la Constitución, reafirmar la paz, proteger bajo su influencia todos los intereses legítimos para desarrollar los grandes recursos de riqueza del país"38. En estas breves líneas, Díaz resume su estrategia o su llamada pax porfiriana, es decir, la política de conciliación que fomentó para lograr su consolidación en el poder y que tiempo después lo convertiría en dictador.

Durante el periodo en el que Porfirio Díaz estuvo en el poder trató de unificar a todas las logias masónicas del rito escocés. La razón principal por la cual Díaz promovió tal unificación fue para llevar a cabo su plan de pacificación nacional al igual que la unificación de varios sectores e instituciones. Sin embargo, ¿Cuáles fueron las estrategias que utilizó? ¿Cómo influyó esto en la pax porfiriana? En esta sección arguyo que Díaz, a pesar de haberse convertido en un dictador, no rompió del todo con los principios liberales que habían impuesto Benito Juárez, Melchor Ocampo, entre otros y que la masonería defendía celosamente. Lo que hizo fue adaptar dichos principios a su propio beneficio y conveniencia para lograr el control total del país y la pacificación del mismo. Por ello, su política de conciliación fue tan exitosa y los masones no se escaparon de ella y por supuesto, tan poco de su control.

\footnotetext{
${ }^{37}$ Luis Zalce Rodríguez, Apuntes para la historia de la masoneria en México: de mis lecturas y mis recuerdos (México D. F.: Talleres Tipográficos de la Penitenciaría del Distrito Federal, 1950), 322.

${ }^{38}$ François-Xavier Guerra, México: del antiguo régimen a la revolución. Tomo I. (México D. F.: Fondo de Cultura Económica, 1991), 214.
} 
Díaz sabía que una estrategia importante era obtener el control de la masonería, específicamente la perteneciente al rito escocés. En la época de Juárez algunas logias masónicas o sus miembros tuvieron considerable influencia en la toma de decisiones. Díaz vio tal influencia con cautela y por ello decidió crear una política conciliatoria para evitar a toda costa cualquier elemento que pudiera hacer tambalear su gobierno. Por tal motivo Díaz siempre vigiló muy de cerca que ni la masonería, ni cualquiera otra institución (como la Iglesia Católica) ganaran terreno político sin su autorización o supervisión. Por ello, la estrategia de Díaz fue tenerlos, ya fuera directa o indirectamente, bajo su control.

La estrategia porfirista hacia la institución masónica se observa claramente en la correspondencia enviada a logias internacionales, particularmente a las logias masónicas en Washington, D.C. y en París, Francia. En dicha comunicación se observa una relación formal y cordial con sus hermanos masones del exterior para lograr cierto reconocimiento hacia las logias de México. Esto era importante para Díaz no solamente para indirectamente contribuir con las logias masónicas mexicanas, sino también para mostrar que en México había una política conciliatoria, orden y progreso. A pesar que Díaz una vez llegando al poder no fue muy activo dentro de la masonería, sí usó dicha filiación como estrategia al inicio de su gobierno ${ }^{39}$.

Dentro de los objetivos de política personalista ${ }^{40}$ que desarrolló Díaz, desde 1876 hasta 1911, se encontraba lograr un control total de todas las instituciones. Su política conciliatoria, también llamada de "pan o palo" era vital identificar a todos aquellos grupos e individuos que pudieran revelarse contra el gobierno o hacerle contrapeso político. Esto lo comprendió el General Díaz desde el inicio de su gobierno, cuando tuvo que buscar recursos económicos para poder derrotar a sus rivales políticos, Lerdo e Iglesias y, de esta manera, reafirmarse en el poder y conservar la posesión de la capital ${ }^{41}$.

Existen diversos factores que le permitieron a Porfirio Díaz controlar las logias masónicas pertenecientes al rito escocés. El hecho que Díaz no haya estado directamente involucrado en las actividades masónicas (como fue el caso de Juárez, por lo que respecta a Díaz eran los masones los que buscaban que se integrara y ellos le pedían que participara en las filas masónicas), le otorgaría una gran ventaja, ya que así, no tendría compromisos

\footnotetext{
${ }^{39}$ Correspondencia con el Gran Oriente de Francia 1876 a 1900. Emilio G. Cantón, Secretario General. Archivo del Gran Oriente de Francia en París.

${ }^{40}$ También debe considerarse el culto que promovió Díaz a su persona y su liderazgo, como propone Roderic Ai Camp. También Camp habla de la tradición personalista que usaron los líderes mexicanos desde Porfirio Díaz hasta Lázaro Cárdenas. Este último fue quien institucionalizó la presidencia en México; es decir, no importa quién sea el presidente, lo que importa es el título, por consiguiente al ser alguien el jefe del ejecutivo se convierte automáticamente en el político más poderoso del país. En el caso de Porfírio Díaz, con el personalismo que desarrolló, no importaba si era o no el presidente (como fue el periodo de 1880-1884 cuando estuvo como presidente Manuel González Aldama), él siempre tuvo el poder. Véase Roderic Ai Camp, Intelectuales y política en México (Oxford: Oxford University Press, 1996), 32-40.

${ }^{41}$ Véase Antonio Lara Téllez, "Compadrazgo Político en el Porfiriato" (Tesis de Licenciatura en Relaciones Internacionales, Universidad de las Américas-Puebla, 1998).
} 
estrechos, ni remordimientos al no seguir sus obligaciones como masón. Si uno se detiene a observar los importantes títulos y grados masónicos que sus hermanos masones le otorgaron a Díaz como Gran Maestre, Diputado Gran Maestre (cabe mencionar que en documentos más tardíos aparece como Gran Maestro honorario) uno diría que estuvo muy involucrado. No obstante, la correspondencia masónica de Díaz con las logias de Francia y Washington señala que son principalmente sus hermanos masones quienes intentan que el presidente participe, que se involucre para el beneficio y prestigio de la institución masónica.

Como lo dice Zalce y Rodríguez y como las cartas antes mencionadas corroboran, Díaz estuvo involucrado tanto en el Rito Nacional Mexicano como en el Rito Escocés. El historiador masónico, Luis Zalce y Rodríguez afirma que Díaz fue iniciado en el Rito Nacional Mexicano y luego se transfiere al Rito Escocés ${ }^{42}$. De esta manera, el estatus de miembro en papel lo ayudó a ejercer cierto control de las logias, mismas que buscaban su aprobación y simpatía. A este respecto el historiador mexicano Luis González y González apunta:

La fuerte personalidad de Díaz contribuyó también a que los masones escoceses aceptaran, en cierta manera, el liderazgo del Gral. Díaz...los logros y triunfos militares que Díaz había obtenido desde 1855 (cuando obtuvo el cargo de jefe político de Ixtlán) demostraron que era un hombre infatigable, dueño de sí mismo, hábil en el uso del palo y el pan, autosuficiente, frío, diplomático, trotamundos y previsor. Es por estas características que se menciona a Díaz como la cabeza de la generación del 'machete', de la cual formaba parte él y el grupo que se arremolinaba a su alrededor ${ }^{43}$.

González y González hace referencia a la personalidad de Díaz y a sus estrategias políticas, claras y firmes para asegurarle el éxito político y el control de las instituciones, entre ellas la masonería. Asimismo, otro aspecto que influyó en el éxito de Díaz ante los 'escoceses' fue que desde un principio, a pesar de sus diferencias, se percató de la popularidad y reputación de Juárez, por ello siempre le dio su lugar, lo usó como símbolo y a la vez aspiró a la reputación de éste y aparentemente iba a perpetuar la gran labor del Benemérito de las Américas ${ }^{44}$. Habiendo sido Juárez un gran masón y considerado por los masones un gran liberal era importante que la gente pensara que seguiría su huella. También Díaz consideró importante incluir a algunos de los miembros del rito escocés en

\footnotetext{
${ }^{42}$ Zalce Rodríguez, Apuntes para la historia de la masoneria en México, 295.

${ }^{43}$ Véase Luis González y González, La ronda de las generaciones (México D.F.: Clío, 1997), 37.

${ }^{44}$ Perry Laurens B. Juárez y Díaz, Continuidad y ruptura en la política mexicana (México D. F.: Era, 1996), 293.
} 
su gabinete, para así poder controlarlos de una manera más cercana y poder ejercer un control institucionalizado ${ }^{45}$.

Un elemento relevante fue la política de conciliación con la Iglesia Católica que Díaz desarrolló durante su gobierno. Tal política no iba de acuerdo con lo que Juárez había logrado, pero Díaz fue cauteloso al principio y posteriormente muy rígido, por lo cual nunca fue atacado abiertamente por los miembros de la masonería. Esto fue una estrategia política para lograr que ningún grupo tuviese fuerza absoluta. Jean Pierre Bastian comenta que "este surgimiento católico provocó una polarización creciente en los pueblos donde había minorías radicales, protestantes, masónicas y espiritistas" ${ }^{\text {" }}$. Sin embargo, Díaz estaba consciente que la masonería podría recuperar el poder e influencia que alguna vez tuvo dentro de la política mexicana, para evitar que esto sucediera accedió a centralizar a la masonería bajo su mando, contribuyendo a la creación de una institución masónica llamada la Gran Dieta Simbólica.

La creación casi indiscriminada de ritos y la disidencia e independencia de ciertas logias dio como consecuencia la creación de la Gran Dieta Simbólica Escocesa de los Estados Unidos Mexicanos en el año de 1890. A fines de 1889, dice el boletín masónico (órgano oficial de la Gran Dieta Simbólica) que el gran Oriente de México, queriendo unir a todos los elementos masónicos de la República, su Gran Logia Valle de México No.1 celebró tratados con el Supremo Consejo del Grado 33 y en virtud de ellos quedó disuelto el Gran Oriente y se fundó la Gran Dieta Simbólica de los Estados Unidos Mexicanos para el régimen exclusivo de los grados de aprendiz, compañero y maestro masón. El 15 de febrero de 1890 quedó solemnemente instituida y se eligió como Gran Maestro al Venerable Hermano Porfirio Díaz, presidente de la República Mexicana ${ }^{47}$. Cabe aclarar, como se mencionó anteriormente, que a pesar de que fue nombrado Gran Maestro, no fue un masón muy activo, más que nada éste fue un cargo honorífico y posteriormente se convierte oficialmente en honorario. Esta relación de conveniencia fue muy importante, pues por un lado, Díaz lograba el control de la masonería y el apoyo de sus miembros y, por otro lado, a los masones les favorecía y agradaba el reconocimiento que Díaz les otorgaba, ya que la simple cercanía con él les abría puertas y les daba cierto prestigio ${ }^{48}$.

\footnotetext{
45 “Una vez llegado el poder, (Díaz), adoptó una política de conciliación, librándose de hombres como Tagle y Benítez, dando acomodo a antiguos lerdistas como Manuel Romero Rubio y Felipe Berriozábal”. Juárez y Díaz, Continuidad y ruptura en la política mexicana, 273.

${ }^{46}$ Jean Pierre Bastian, Protestantes, liberales y francmasones. Sociedades de ideas y modernidad en América Latina, siglo XIX (México D. F.: FCE, 1990), 148.

${ }^{47}$ Félix Navarrete, La masonería en la historia y en las leyes de Méjico (México D. F.: Editorial Jus, 1962), 120.

${ }^{48}$ Para una discusión más profunda sobre la Gran Dieta Simbólica, véase, Paul Rich y Guillermo de los Reyes, "Policy Making and the Control of the Nongovernmental Sector: Porfirio Díaz and the Grand Diet," Review of Policy Research 22, no. 5 (2005): 721-725.
} 


\section{Conclusión}

Díaz se involucró en la masonería como apoyo para su pax porfiriana. El dictador estaba consciente de la importancia que los masones le dan a los lazos fraternales y el apoyo mutuo. Por otro lado, al ver las tensiones entre la masonería y la Iglesia Católica, con el fin de evitar que resurgiera el conflicto convenció a los masones que al formar parte de la masonería velaría por los intereses seculares del estado. Cabe mencionar que la política de Díaz tuvo su éxito ya que no hubo ni crisis, ni tensiones importantes entre la masonería y la Iglesia, como sucedió décadas antes o como sucedería en la década de los años veinte del siguiente siglo. Las ideas de Díaz eran pragmáticas al darle cierta oportunidad a cada grupo pero manteniendo siempre el control.

La masonería, como se discutió anteriormente, fue una de las instituciones que utilizó el general Díaz para poder extender su poder y, de esta manera, tener controlados todos los sectores de la sociedad. Si se observa detalladamente lo que estaba sucediendo entre las filas masónicas es evidente que la idea de Díaz de unir a todos los masones tuvo ventajas políticas. Díaz, como apunta Luis Zalce, pretendió dar "una apariencia liberal...para "conocer mejor" a aquellos que decían ser "sus nuevos amigos" y para observar más de cerca a los descontentos, congregándolos en lugares donde los menos precavidos revelarían sus sentimientos más íntimos, desahogándose de manera segura"49.

La relación que se desarrolló entre la francmasonería y Porfirio Díaz fue positiva. El salvamento por parte de sus hermanos masones en el vapor, "City of Havana", fue un momento pivote en la vida política de Díaz, ya que gracias a la fraternidad y solidaridad de sus hermanos masones, Díaz pudo continuar con sus ambiciones políticas Esta dinámica se ve cristalizada en la estrategia que más tarde utilizó para favorecer su pax porfiriana. La evidencia sugiere que la masonería fue empleada como instrumento durante la mayor parte de su administración -Díaz, al momento de convertirse en dictador no estaba tan convencido de la lealtad de sus hermanos masones, a pesar de la experiencia tan positiva que tuve al ser salvado en Tampico y Veracruz. Los masones fueron efectivamente reclutados por Díaz como parte de su base de poder para tenerlos de cerca y evitar cualquier tipo de disidencia. La francmasonería proveería la certeza de que Díaz era un liberal (aunque no lo fuera), a pesar de que para muchos era pragmático y conservador. En todo caso Díaz no vio la masonería como un arma contra el catolicismo, como fue el caso de algunos de sus predecesores. A Díaz le importaba que la masonería fuera su aliada para poder tener un gobierno lleno de paz, orden y progreso en el que el jugo el papel del gran arquitecto de la República Mexicana.

\footnotetext{
${ }^{49}$ Zalce Rodríguez, Apuntes para la historia de la masoneria en México, 321.
} 


\section{Fuentes}

“A Master Mason's Word of Honor and a Brother who Refused Fifty Thousand Dollars for it, Alexander K. Coney, Preceding Remarks by the Speaker". Gran Logia de California, Archivo 17, s/f.

Correspondencia con el Gran Oriente de Francia 1876 a 1900. Emilio G. Cantón, Secretario General. Archivo del Gran Oriente de Francia en París.

Díaz, Porfirio. Archivo del general Porfirio Díaz, memorias y documentos; prólogo y notas de Alberto María Carreño. México D.F.: Editorial "Elede", 1947.

"El salvamento de Don Porfirio Díaz frente a la barra de Tampico", Testimonio de Manuel Gutiérrez Zamora, propiedad de la familia Gutiérrez Zamora. Véase: Manuel Gutiérrez Zamora, Historia mexicana 5, no. 1 [17] (jul. sept., 1955): 62-85.

\section{Bibliografía}

Anderson, Benedict. Imagined Communities: Reflections on the Origin and Spread of Nationalism. New York: Verso, 1983.

Aubert, Roger. The Church in the Industrial Age. Londres: Burns \& Oates, 1981.

Bastian, Jean Pierre. Protestantes, liberales y francmasones. Sociedades de ideas y modernidad en América Latina, siglo XIX. México D. F.: FCE, 1990.

Bennett, Brian J. "El Primer Masón Aborigen Australiano". Newsletter. Logia de Investigación CC, Irlanda, 1992, s. p.

Coil, Henry Wilson. Coil's Masonic Encyclopedia. Editado por William Moseley Brown. Richmond, VA: Macoy Publishing \& Masonic Supply Company, Macoy Publishing \& Masonic Supply Company, 1961.

Camp, Roderic A. Los intelectuales y el estado en el México del siglo XX. Oxford: Oxford University Press, 1996.

De los Reyes, Guillermo. "Freemasonry and Folklore in Mexican Presidentialism". Journal of American Culture 20, no. 2 (1997): 61-69.

De los Reyes, Guillermo. Herencias secretas: Masonería, política y sociedad en México. México D.F.: Benemérita Universidad Autónoma de Puebla, 2009.

Denslow, William R. 10,000 famous Freemasons. Richmond, VA: Macoy Pub. and Masonic Supply, 1957.

Díaz, Porfirio. Archivo del general Porfirio Díaz, memorias y documentos; prólogo y notas de Alberto María Carreño. México D. F.: Editorial Elede, 1947.

Ferrer Benimeli, José Antonio. Bibliografía de la masonería: introducción históricocrítica. Madrid: Fundación Universitaria Española, 1977.

Flores Zavala, Marco Antonio. "Los ciclos de la masonería mexicana”. En La Masonería 
en Madrid y en España del siglo XVIII al XXI. Coordinado por José Antonio Ferrer Benimeli. Zaragoza: CEHME, 2004.

González y González, Luis. La ronda de las generaciones. México D. F.: Clío, 1997.

Guerra, François-Xavier. México: del antiguo régimen a la revolución. Tomo I. México D. F.: Fondo de Cultura Económica, 1991.

Gutiérrez Zamora, Manuel. "El salvamento de Don Porfirio Díaz frente a la barra de Tampico". Historia mexicana 15, no. 17 (1955): 62-85.

Lara Téllez, Antonio. "Compadrazgo político en el porfiriato". Tesis de Licenciatura en Relaciones Internacionales, Universidad de las Américas-Puebla, 1998.

López, Herculano. Cartas Pastorales. Morelia: Imp. de San Ignacio, 1887.

Meyer, Michael y Sherman William. The Course of Mexican History. New York: Oxford University Press, 1987.

Knight, Alan. The Mexican Revolution: Porfirians, Liberals, and Peasants. Lincoln: University of Nebraska Press, 1986 [1990].

Navarrete, Félix. La masonería en la historia y en las leyes de Méjico. México D. F.: Editorial Jus, 1962.

Perry, Laurens B. Juárez y Díaz: continuidad y ruptura en la política mexicana. México D. F.: Era, 1996.

Rich, Paul y Guillermo de los Reyes. "Policy Making and the Control of the Nongovernmental Sector: Porfirio Díaz and the Grand Diet." Review of Policy Research 22, no. 5 (2005): 721-725.

Smart, Ninian. "Lands of Hope and Glory". Times Higher Education Supplement. 2 de febrero de 1990.

Speckman Guerra, Elisa. "El Porfiriato". En Nueva historia mínima de México. México D. F.: El Colegio de México, 2011.

Zalce y Rodríguez, Luis J. Apuntes para la historia de la masoneria en México (de mis lecturas y mis recuerdos). Mexico D. F.: [Talleres Tipográficos de la Penitenciaría del Distrito Federal], 1950. 